REVIEW ARTICLE
A. Rovira
J. Alonso
J. Córdoba

\section{MR Imaging Findings in Hepatic Encephalopathy}

\begin{abstract}
SUMmARY: The term hepatic encephalopathy (HE) includes a spectrum of neuropsychiatric abnormalities occurring in patients with liver dysfunction. Most cases are associated with cirrhosis and portal hypertension or portal-systemic shunts, but the condition can also be seen in patients with acute liver failure and, rarely, with portal-systemic bypass and no associated intrinsic hepatocellular disease. Although $\mathrm{HE}$ is a clinical condition, several neuroimaging techniques, particularly MR imaging, may eventually be useful for the diagnosis because they can identify and measure the consequences of central nervous system (CNS) increase in substances that under normal circumstances, are efficiently metabolized by the liver. Classic MR imaging abnormalities include high signal intensity in the globus pallidum on T1-weighted images, likely a reflection of increased tissue concentrations of manganese, and an elevated glutamine/glutamate peak coupled with decreased myo-inositol and choline signals on proton MR spectroscopy, representing disturbances in cell-volume homeostasis secondary to brain hyperammonemia. Recent data have shown that white matter abnormalities, also related to increased CNS ammonia concentration, can also be detected with several MR imaging techniques such as magnetization transfer ratio measurements, fast fluid-attenuated inversion recovery sequences, and diffusion-weighted images. All these MR imaging abnormalities, which return to normal with restoration of liver function, probably reflect the presence of mild diffuse brain edema, which seems to play an essential role in the pathogenesis of HE. It is likely that MR imaging will be increasingly used to evaluate the mechanisms involved in the pathogenesis of $\mathrm{HE}$ and to assess the effects of therapeutic
\end{abstract} measures focused on correcting brain edema in these patients.
H epatic encephalopathy (HE) reflects a spectrum of neuropsychiatric abnormalities occurring in patients with liver dysfunction. Most cases are associated with cirrhosis and portal hypertension or portal-systemic shunts, but the condition can also be seen in patients with acute liver failure and, rarely, with portal-systemic bypass and no associated intrinsic hepatocellular disease. ${ }^{1,2}$ The most common clinical pattern in these patients is the development of confusion or coma precipitated by gastrointestinal bleeding, acute superimposed hepatitis, or concomitant infection in a previously asymptomatic patient with cirrhosis. The neurologic manifestations are mainly due to shunt of blood arising from the portal venous bed into the systemic circulation and are reversible once the liver function abnormality or precipitating factor has been corrected. HE can be classified according to the underlying liver disease and the evolution of the neurologic manifestations (Table 1).

\section{Clinical Features}

Clinically, HE manifests as a neuropsychiatric syndrome encompassing a wide spectrum of mental and motor disorders. ${ }^{2,3}$ The changes in mental status range from subtle cognitive dysfunction to severe coma, whereas the motor function changes include rigidity, disorders of speech production, resting- and movement-induced tremor, delayed diadochokinetic movements, hyper- or hyporeflexia, choreoathetoid movements, Babinski sign, and transient focal symptoms. ${ }^{3-7} \mathrm{HE}$ can

Received January 29, 2008; accepted January 30.

From the Magnetic Resonance Unit (Institut de Diagnostic per La Imatge) (A.R., J.A.), Department of Radiology, Hospital Universitari Vall d'Hebron, Barcelona, Spain; Centro de Investigación Biomédica en Red de Enfermedades Hepáticas y Digestivas (CIBEREHD) (J.A., J.C.), Madrid, Spain; Liver Unit (J.C.), Department of Internal Medicine, Hospital Universitari Vall d'Hebron, Barcelona, Spain; and Department of Medicine (J.C.), Autonomous University of Barcelona, Cerdanyola del Vallès, Spain.

Please address correspondence to Alex Rovira Cañellas, MD, Unitat de Ressonància Magnètica, Servei de Radiologìa, Hospital Universitari Vall d'Hebron, Pg. Vall d'Hebron 119-129, Barcelona 08035 Spain; e-mail: alex.rovira@idi-cat.org

DOI 10.3174/ajnr.A1139 be classified into 3 main groups on the basis of the duration and characteristics of the clinical manifestations ${ }^{2}$ : episodic, chronic, and minimal.

\section{Episodic HE}

Episodic HE is characterized by the development of a confusional syndrome, including impaired mental state, neuromuscular abnormalities, asterixis, fetor hepaticus, and hyperventilation, which develops during a short period of time and fluctuates in severity. The diagnosis of episodic HE, which requires the exclusion of a pre-existing or evolving dementia, is based on clinical findings and relies on the presence of consistent neurologic manifestations in a patient with severe liver failure and/or portal-systemic shunt surgery. There are no available diagnostic tests to confirm clinically suspected HE. Arterial ammonia analysis adds nothing to the diagnosis of typical patients but is sometimes the clue for diagnosing atypical patients, particularly those with no previous history of liver disease. Neuroimaging techniques also have limited diagnostic value but are required in some atypical patients to exclude other neurologic diseases that can exhibit similar clinical manifestations, such as metabolic encephalopathies, stroke, seizure, meningitis, or encephalitis.

\section{Chronic HE}

Chronic HE can be subclassified into relapsing HE and persistent HE. Relapsing HE manifests as frequent episodes of acute HE that may be due to precipitating factors (gastrointestinal hemorrhage, uremia, use of psychoactive medication or diuretics increasing renal ammonia release, dietary indiscretion, infection, constipation, dehydration, hypo- or hyperkalemia, and hyponatremia) but, in most cases, are spontaneous or related to discontinuation of medication. Between acute episodes of HE, which do not differ from those described previously for episodic HE, the patient can be perfectly alert and not show any sign of cognitive dysfunction. However, a careful neurologic examination and neuropsychological tests may re- 


\begin{tabular}{|c|c|c|c|c|}
\hline HE & $\begin{array}{l}\text { Liver } \\
\text { Disease }\end{array}$ & $\begin{array}{l}\text { Extrahepatic Portal- } \\
\text { Systemic Shunting }\end{array}$ & $\begin{array}{c}\text { Neurologic } \\
\text { Manifestations }\end{array}$ & Specific Features \\
\hline \multicolumn{5}{|l|}{ Acute episode } \\
\hline In cirrhosis & Cirrhosis & Variable & $\begin{array}{l}\text { Acute confusional state to } \\
\text { coma }\end{array}$ & Usually precipitated \\
\hline In acute liver failure & $\begin{array}{l}\text { Acute liver } \\
\text { failure }\end{array}$ & Absent & $\begin{array}{l}\text { Acute confusional state to } \\
\text { coma }\end{array}$ & $\begin{array}{l}\text { Frequently complicated by brain edema } \\
\text { and intracranial hypertension }\end{array}$ \\
\hline \multicolumn{5}{|r|}{ 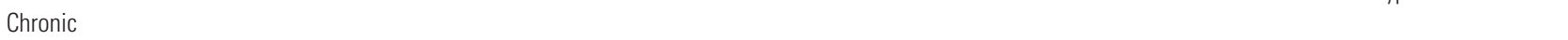 } \\
\hline Relapsing & Cirrhosis & Severe & $\begin{array}{l}\text { Relapsing episodes of } \\
\text { encephalopathy }\end{array}$ & Usually without precipitating factors \\
\hline Persistent & Cirrhosis & Severe & $\begin{array}{l}\text { Persistent cognitive or } \\
\text { motor abnormalities }\end{array}$ & $\begin{array}{l}\text { Generally related to surgically induced } \\
\text { shunts }\end{array}$ \\
\hline Minimal HE & Cirrhosis & Variable & Asymptomatic & $\begin{array}{c}\text { Abnormalities revealed by } \\
\text { neuropsychological or } \\
\text { neurophysiologic tests }\end{array}$ \\
\hline $\begin{array}{l}\text { In patients with portal-systemic } \\
\text { bypass with no intrinsic } \\
\text { hepatocellular disease }\end{array}$ & Absent & Large shunts & $\begin{array}{l}\text { Relapsing episodes and } \\
\text { persistent abnormalities }\end{array}$ & $\begin{array}{l}\text { Rare disorder, secondary to congenital } \\
\text { abnormalities, surgical shunts, or } \\
\text { portal vein thrombosis }\end{array}$ \\
\hline
\end{tabular}

\begin{tabular}{lc}
\hline Table 2: West Haven criteria for semiquantitative grading of HE \\
\hline $\begin{array}{l}\text { Grade } \\
\text { Trivial lack of awareness, euphoria or anxiety, shortened attention } \\
\text { span, impaired performance of addition (Sixty-seven percent of } \\
\text { patients with cirrhosis may have minimal HE.) } \\
\text { Lethargy or apathy, minimal disorientation for time or place, } \\
\text { subtle personality change, inappropriate behavior, impaired } \\
\text { performance of subtraction }\end{array}$ \\
$\begin{array}{l}\text { Somnolence to semistupor, but responsive to verbal stimuli; } \\
\text { confusion; gross disorientation }\end{array}$ \\
\hline
\end{tabular}

veal subtle abnormalities, such as extrapyramidal signs and mild cognitive impairment.

Persistent HE refers to manifestations that do not reverse despite adequate treatment. Assessment of the severity of persistent HE is based on the West Haven criteria for semiquantitative grading of mental status, which consider the level of impaired autonomy, changes in consciousness, intellectual function and behavior, and dependence on therapy (Table 2). ${ }^{2}$

The most characteristic manifestations of severe persistent HE are dementia, parkinsonism, or myelopathy in combination with other manifestations of neurologic involvement (ataxia, gait abnormalities, tremor). This clinical picture is seldom seen currently because of the availability of liver transplantation and the small number of patients who undergo portal-systemic shunt surgery.

\section{Minimal HE}

Minimal HE, also known as latent or subclinical HE, refers to the population of patients with cirrhosis or portal-systemic shunts who have subtly abnormal cognitive and/or neurophysiologic function. These abnormalities cannot be detected by standard clinical examination ${ }^{8}$ but may produce clinical consequences because they have a detrimental impact on health-related quality of life and on the ability to perform complex tasks such as driving. ${ }^{9}$

The absence of clinical evidence of HE is key to the diagnosis of minimal HE and can only be determined by a detailed assessment of the patient's history and a comprehensive neurologic evaluation of consciousness and cognitive and motor functions. The neuropsychological features of minimal $\mathrm{HE}$ point to a disorder of executive functioning, particularly selective attention and psychomotor speed, but other abnormalities are also seen. ${ }^{9,10}$ A complete psychometric assessment by a neuropsychologist is the best way to know the extent of the patient's cognitive impairment and how it interferes with daily life. However, this evaluation is not easy to carry out because of the cost, complexity, and length of the study. Diagnostic methods that demonstrate central nervous system (CNS) abnormalities attributable to liver failure in a patient with no clinical evidence of HE would be valid as an alternative diagnostic method for minimal HE. Unfortunately, to our knowledge, an arbitrary consensus to define a gold standard to compare the reliability of the different methods has not been reached. The current recommendation is to apply short batteries of diagnostic neuropsychological tests adapted to the cultural characteristics of the population being evaluated. Several neuroimaging techniques such as single-photon emission $\mathrm{CT}$, positron-emission tomography, and MR imaging have shown abnormalities in cerebral blood flow, brain metabolism, and brain structure in patients with minimal HE. ${ }^{11}$ However these abnormalities reflect the pathogenic process that underlies the condition, rather than providing diagnostic information.

\section{Pathogenesis of HE}

Various hypotheses have been proposed to explain the complex neuropsychiatric syndrome seen in HE. The clinical manifestations of HE appear to reflect primarily a shift in the balance between inhibitory and excitatory neurotransmission toward a net increase of the former, as a consequence of at least 2 factors. The first is downregulation of glutamate receptors following excessive extrasynaptic glutamate accumulation resulting from impaired re-uptake into nerve endings and astrocytes (liver failure inactivates the glutamate transporter in astrocytes). The second factor is an increase in inhibitory neurotransmission due to increased levels of natural benzodiazepines and increased availability of GABA-aminobutyric acid. $^{12,13}$

Pathogenic mechanisms that may be responsible for HE include accumulation in blood of several compounds that are efficiently metabolized by the liver under normal circum- 

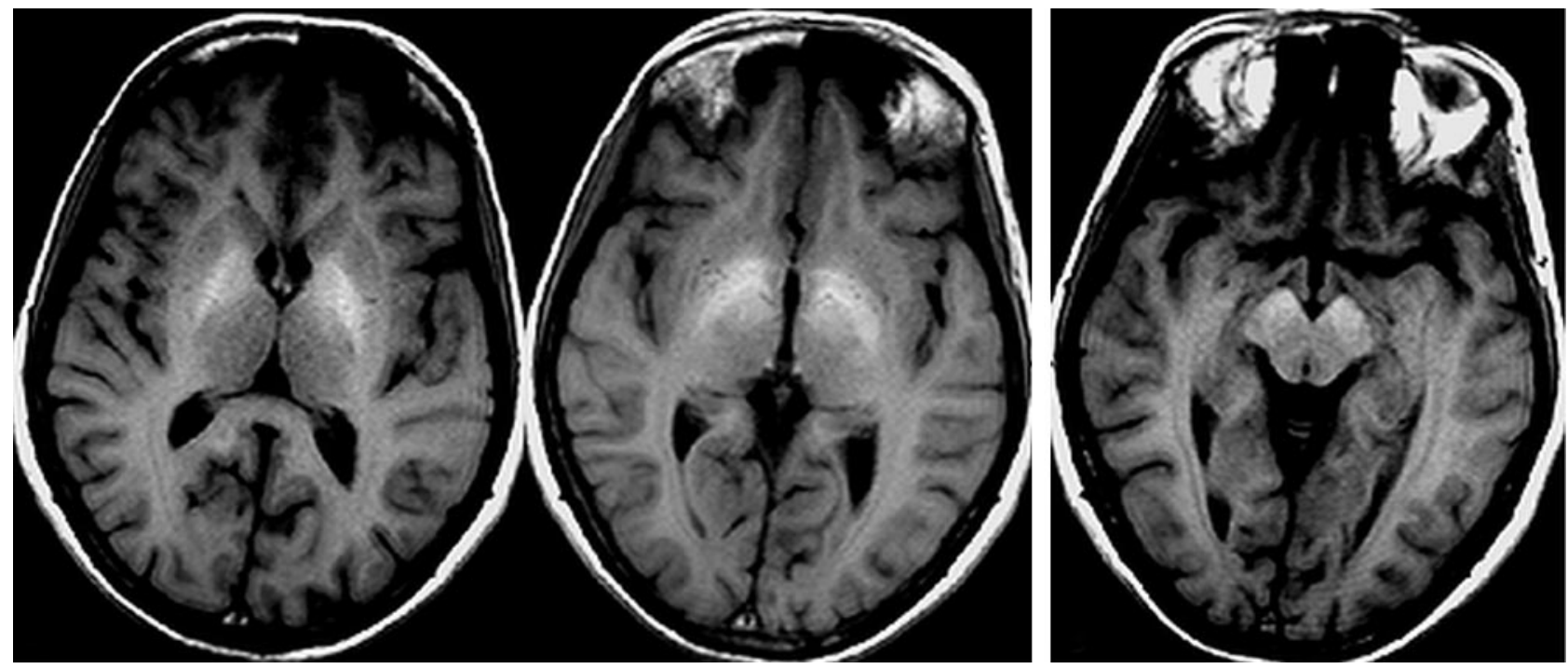

Fig 1. Transverse $T 1$-weighted MR images of the brain in a patient with chronic liver failure and parkinsonism. Observe the bilateral and symmetric high $\mathrm{T} 1$ signal-intensity change involving the globus pallidus and the anterior midbrain.

stances, such as manganese and ammonia, which then enter the brain where they induce disturbances in astrocyte and neuron function. ${ }^{14-17}$

\section{Manganese}

The CNS is an important target for manganese, an essential element that is normally excreted via the hepatobiliary route. ${ }^{18}$ Manganese has a key role in the normal functioning of several enzymes including mitochondrial superoxide dismutase, glutamine synthetase, and phosphoenolpyruvate carboxykinase. ${ }^{19-21}$ The metal was first considered to be neurotoxic more than 150 years ago, when workers employed in grinding black oxide of manganese developed an unsteady gait and muscle weakness. ${ }^{22}$ Since that time, many cases of manganese neurotoxicity (manganism), a neurologic disease characterized by psychological and neurologic abnormalities, with some similarities to Parkinson disease, have been reported, particularly in miners, smelters, welders, and workers involved in the alloy industry. ${ }^{23-25}$ Typically, patients exhibit extrapyramidal changes that include hypokinesia, rigidity, and tremor.

In patients with cirrhosis or portal-systemic shunts, manganese is elevated in plasma and is then transferred to the brain through the blood-brain barrier by several transport systems. This increase in brain manganese has a neurotoxic effect, inducing selective neuronal loss in basal ganglia structures and reactive gliosis. These effects are more prominent in the globus pallidus (particularly the medial segment), the substantia nigra reticulata, and, to a lesser extent, the striatum, with sparing of the substantia nigra pars compacta neurons and striatal dopamine. ${ }^{14,26-28}$ This selective vulnerability of basal ganglia structures probably explains the development of parkinsonian manifestations (bradykinesia, rigidity) in $\mathrm{HE},{ }^{29}$ which are chronic and usually mild.

Parkinsonian manifestations in HE can be distinguished from idiopathic Parkinson disease by early gait and balance dysfunction, relative absence of resting tremor, presence of mild cognitive impairment at the time of presentation, ele- vated serum manganese levels, and little or no response to levodopa. ${ }^{30-34}$ These differences can be partially explained by the fact that manganese preferentially produces pallidal degeneration, while sparing the nigrostriatal system, in contrast to Parkinson disease, which preferentially damages dopaminergic neurons in the substantia nigra pars compacta. ${ }^{31}$

\section{MR Imaging Marker of Manganese Accumulation within the CNS}

Since the introduction of MR imaging in clinical practice, the fact that most patients with cirrhosis or portal-systemic shunts exhibit a bilateral symmetric high signal intensity at the globus pallidus and substantia nigra has been well described (Fig 1). ${ }^{35,36}$ The signal intensity may increase after a transjugular intrahepatic portal-systemic stent shunt surgery with transjugular intrahepatic portal-systemic stent placement ${ }^{37}$ and reverses after normalization of liver function ${ }^{36}$ or after occlusion of congenital portal-systemic shunts. ${ }^{38}$ The most plausible explanation for the increased T1 signal intensity is a rise in manganese concentration (a paramagnetic substance) in the CNS, with preferential deposition in the globus pallidus. ${ }^{39}$ The arguments favoring the manganese hypothesis include the dramatic blood and CSF manganese increase in patients with cirrhosis and pallidal hyperintensities, ${ }^{40-42}$ normalization of MR imaging signal intensity abnormalities and manganese levels after liver transplantation, ${ }^{36}$ and the severalfold increase in manganese concentrations from pallidal samples obtained at autopsy in patients with cirrhosis. ${ }^{43,44}$

This manganese-related MR imaging signal-intensity abnormality has also been described in patients without cirrhosis, such as those receiving total parenteral nutrition, ${ }^{45-48}$ those with occupational exposure to manganese from welding, ${ }^{49}$ and those with noncirrhotic portal vein thrombosis or congenital portal-systemic bypass and no intrinsic hepatocellular disease. ${ }^{50-52}$ In all these situations, the MR imaging signal-intensity changes resolve after discontinuation of manganese intake. ${ }^{45-47}$ Similar findings were observed in a patient with Alagille syndrome, ${ }^{53}$ an autosomal dominant disorder 
characterized by cholestasis, intrahepatic bile duct paucity, end stage liver disease, and elevated blood manganese.

Bilateral basal ganglia $\mathrm{T} 1$ signal-intensity changes have also been observed in several conditions unrelated to increased brain manganese levels (eg, nonketotic hyperglycemic episodes, hypoxic-ischemic encephalopathy, basal ganglia calcification, neurofibromatosis type I, and Japanese encephalitis), though the high signal intensity occurring in these conditions does not usually show symmetric predominantly pallidal involvement. ${ }^{54}$

Although pallidal hyperintensities are found in approximately $90 \%$ of patients with cirrhosis, these signal-intensity alterations are not closely linked to the presence of HE. Patients with cirrhosis and no clinical, neuropsychological, or neurophysiologic signs of HE can also show severe signal-intensity alterations, whereas others with manifest HE may present only slight signal-intensity alterations. ${ }^{55,56}$ Moreover, longitudinal studies have shown quick regression of HE after liver transplantation, whereas T1 signal intensity abnormalities need up to 1 year to resolve. ${ }^{56-59}$ This clinical MR imaging discrepancy may be explained by the fact that $\mathrm{T} 1$ high signal intensity cannot be used as a quantitative measure of tissue manganese because it represents only a semiquantitative measurement of abnormal manganese deposition. Thus, it is possible that manganese accumulation participates in the pathogenesis of HE only after reaching a certain degree, which may not be clearly identified by MR imaging. Recent data support the concept that the presence of parkinsonism is related to the extension of the high signal intensity to midbrain structures (particularly the substantia nigra) because this MR imaging feature is unique to patients with cirrhosis-related parkinsonism (Fig 1). ${ }^{30}$

\section{Ammonia}

The main source of ammonia is the gut, and an important amount is of bacterial origin. ${ }^{60}$ The concentration of ammonia in portal blood is high and undergoes a high degree of extraction in the liver (90\%). Patients with liver failure or portal-systemic shunt surgery have elevated levels of circulating ammonia, which enters the brain through the blood-brain barrier, increasing the brain-blood ammonia concentration ratio (normally in the order of 2) up to fourfold in liver failure. Positron-emission tomography studies by using nitrogen-13 ammonia provide evidence of the increased blood-brain ammonia transfer and brain ammonia utilization rates in patients with chronic liver failure. ${ }^{61}$ This hyperammonemia results in profound astrocyte changes, including Alzheimer type II changes in chronic HE and astrocyte swelling in acute HE. In fact, brain edema and increased intracranial pressure are the most important and well-recognized complications of fulminant hepatic failure. The mechanism for astrocyte swelling in acute liver failure remains uncertain but is likely to include excessive generation of osmolytes, mainly glutamine, within the astrocytes ${ }^{62}$ as a result of ammonia detoxification through the action of glutamine synthetase. Additionally, abnormalities in intracellular $\mathrm{pH}$ and membrane potential can disrupt ion homeostasis and lead to cell swelling. ${ }^{63}$

Nevertheless, although cerebral glutamine increases to a similar extent in both acute and chronic liver failure, brain edema and death from intracranial hypertension are only

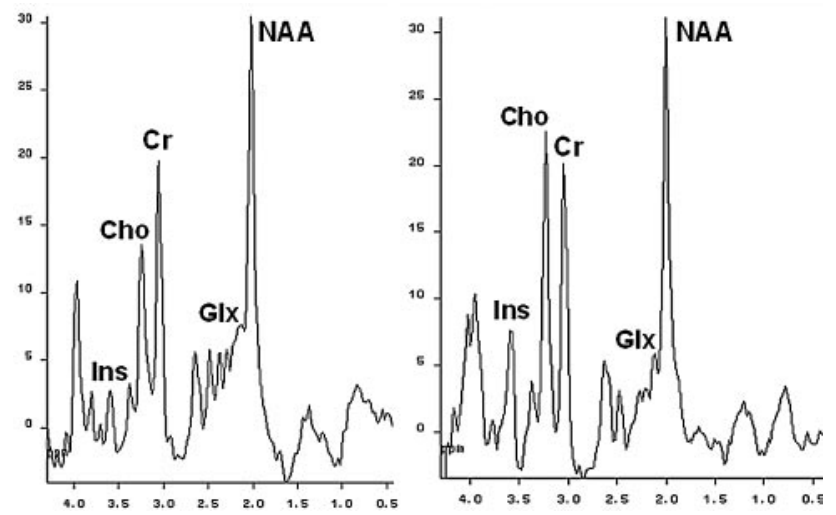

Fig 2. ${ }^{1} \mathrm{H}-\mathrm{MR}$-spectroscopy water-suppressed proton spectra of an 8-mL voxel located in the parietal region including predominantly normal-appearing white matter in a patient with cirrhosis before (left) and after (right) liver transplantation, recorded with a stimulated echo acquisition mode pulse sequence (TR/TE, 1600/20 ms; acquisitions, 256). The main resonances correspond to $\mathrm{N}$-acetylaspartate (NAA, $2.0 \mathrm{ppm}$ ), glutamine/glutamate (GlX, 2.1-2.5 ppm), creatine/phosphocreatine ( $\mathrm{Cr}, 3.02 \mathrm{ppm}$ ), choline-containing compounds (Cho, $3.2 \mathrm{ppm})$, and myo-inositol (Ins, $3.55 \mathrm{ppm}$ ). The initial spectrum shows an increase in the glutamate/glutamine region and a decrease in the myo-inositol and choline resonances. These abnormalities normalized after liver transplantation. Normal NAA indices are seen in both examinations.

rarely complications of chronic liver failure. ${ }^{64}$ One possible explanation for this observation is that the relatively more rapid evolution of the syndrome in fulminant hepatic failure may not allow homeostatic compensatory metabolic changes to counteract the osmotic unbalance induced by intra-astrocytic glutamine accumulation. In chronic liver failure, there is enough time for activation of effective compensatory mechanisms of cellular adaptation to the osmotic change ${ }^{65}$ : glial accumulation of 1 organic osmolyte, glutamine, should lead to the loss of other organic osmolytes, such as myo-inositol, taurine, and choline. ${ }^{66}$ In patients with cirrhosis subjected to ammonia load, this mechanism of osmolar adaptation is clearly reflected in proton MR spectroscopy ( ${ }^{1} \mathrm{H}-\mathrm{MR}$ spectroscopy) studies, which consistently show increases in the glutamine/ glutamate signal intensity accompanied by myo-inositol depletion and decreases in the choline signal intensity (Fig 2) ${ }^{67-73}$ This osmoregulatory mechanism is activated after liver failure and accounts for the protection against massive edema in chronic liver failure. ${ }^{74}$

The extent of the ${ }^{1} \mathrm{H}$-MR spectroscopy alterations increases with increasing grade of HE, though these changes have also been observed in patients with cirrhosis and neither clinical nor psychometric or neurophysiologic signs of cerebral dysfunction. ${ }^{73}$ Lee et al ${ }^{68}$ reported no differences in ${ }^{1} \mathrm{H}$-MR spectroscopy findings between patients with and without $\mathrm{HE}$ and a similar extent of liver dysfunction. Thus, the characteristic ${ }^{1} \mathrm{H}-\mathrm{MR}$ spectroscopic changes seem to reflect metabolic more than functional brain alterations.

Some studies assessing the evolution of ${ }^{1} \mathrm{H}-\mathrm{MR}$ spectroscopic abnormalities after liver transplantation ${ }^{57,58,75}$ have demonstrated their reversibility after liver failure is corrected (Fig 2), though the evolution of these changes differs for each metabolite. The choline peak normalizes earlier than the other peaks and at 1-2 months may even show a small increment over normal values. The glutamine/glutamate peak reaches the normal range at 1-2 months, except in patients with higher pretransplant values, who may take longer. ${ }^{58,59}$ The peak myo- 
inositol abnormalities normalize slower than the other peaks and may take 3-7 months to reach normal values. This reversibility of ${ }^{1} \mathrm{H}$-MR spectroscopic abnormalities precedes the disappearance of pallidal hyperintensity after liver transplantation or after occlusion of large portal-systemic shunts ${ }^{58}$ and correlates with improvements in the neurologic manifestations of HE. ${ }^{76}$

\section{Diffuse Brain Edema in Chronic Liver Failure}

Recent data suggest that despite the adaptive response to increased glutamine concentration, mild astrocyte swelling occurs in the entire spectrum of liver disease and may be partially responsible for the development of $\mathrm{HE}$ in chronic liver disease. ${ }^{74,77,78} \mathrm{~A}$ few reports have described brain edema in patients with cirrhosis ${ }^{64,79}$ and astrocyte swelling in animal models of minimal HE. ${ }^{80}$ In addition, the Alzheimer type II astrocyte, the characteristic neuropathologic finding in patients with cirrhosis, represents a swollen astrocyte, which can be regarded as a manifestation of cerebral edema associated with chronic liver failure. ${ }^{81}$ However, conventional MR imaging techniques have not revealed T2-weighted signal-intensity abnormalities within the brain indicating the presence of cerebral edema. Different MR imaging techniques, such as magnetization transfer (MT) imaging, ${ }^{57,82,83}$ fast fluid-attenuated inversion recovery (FLAIR) imaging, ${ }^{84}$ and diffusionweighted imaging (DWI), ${ }^{85,86}$ which are much more sensitive to changes in brain tissue water content than conventional T2 sequences, have been recently applied for examination of the brain in patients with cirrhosis to obtain data on the attractive hypothesis of the presence of diffuse brain edema, related to hyperammonemia, in patients with chronic liver disease.

\section{MT Imaging}

MT imaging is mainly based on the interaction (cross-relaxation) between protons in a relatively free environment (bulk water) and those in which motion is restricted (immobile water). ${ }^{87}$ Exchange of this saturated magnetization with free water reduces the signal intensity observed in the subsequent MR image. The degree of signal-intensity loss depends on the attenuation of the macromolecules in a given tissue. Low MT ratios (MTRs) indicate reductions in brain structures able to exchange magnetization with the surrounding water molecules and thereby reflect myelin damage, cell destruction, or changes in water content. Experimental and human studies support the hypothesis that demyelination and axonal loss are the main contributors to the MTR decrease seen in several pathologic conditions, such as experimental autoimmune encephalomyelitis, toxic demyelination, progressive multifocal leukoencephalopathy, human immunodeficiency virus encephalitis, and multiple sclerosis. ${ }^{88-92}$ Severe MTR decrease correlates directly with the severity of demyelination and axonal loss, but less severe decrease is more difficult to interpret because inflammation, edema, and moderate demyelination can also contribute to these MTR values.

Different studies have assessed MTR in the brain of patients with cirrhosis. ${ }^{57,82,83}$ All these works found low MTR values in all the examined regions of the CNS. Compared with other diseases, the MTR decrease is mild (approximately 10\%) and is not accompanied by significant abnormalities on conventional T1- and T2-weighted images. This MTR decrease al- most returns to normal values after liver transplantation, thus supporting the hypothesis that these changes reflect mild brain edema. ${ }^{57}$ Another explanation for MTR decreases has been proposed by Iwasa et $\mathrm{al}^{93}$ in a study focusing on basal ganglia abnormalities. On the basis of the correlation between MTR and manganese concentration in phantom experiments, the authors proposed that MTR decreases could be secondary to the accumulation of manganese in the CNS. However, MTR improves rapidly after liver transplantation, whereas pallidal hyperintensity shows a slower disappearance, ${ }^{49}$ in keeping with the time course of normalization after manganese intoxication. ${ }^{47}$ Furthermore, MTR is low in all brain regions, whereas manganese accumulation predominates in the globus pallidum. ${ }^{29}$ The issue of whether the mild brain edema detected by MTR participates in the development of neurologic manifestations is still unresolved. Although a correlation between MTR values and neuropsychological function has not been demonstrated in chronic liver disease, it has been shown that MTR normalization progresses in parallel with the correction of neuropsychological disturbances after liver transplantation. ${ }^{57}$

\section{Fast FLAIR Sequences}

Conventional MR imaging is not sensitive enough to detect slight diffuse increases in brain water content. Nonetheless, the following novel MR imaging finding in patients with chronic liver failure has been described: high signal intensity along the hemispheric white matter in or around the corticospinal tract on fast FLAIR T2-weighted images, strikingly similar to signal-intensity abnormalities noted in cases of amyotrophic lateral sclerosis (Fig 3). ${ }^{84,94}$ Two possible explanations were given for this previously undescribed signal-intensity abnormality in patients with liver cirrhosis: first, the use of fast FLAIR, a sequence that (at least in the supratentorial compartment) has demonstrated higher sensitivity than conventional T2-weighted sequences for depicting white matter lesions (WMLs). ${ }^{95}$ Second, these abnormalities might have been interpreted as a normal finding because fast FLAIR sequences are able to trace the corticospinal tract as a faint symmetric signal-intensity increase in approximately half of healthy adults. ${ }^{96,97}$ However, the progressive normalization of this signal-intensity abnormality with improvement of liver function excluded this second interpretation (Fig 3). ${ }^{84}$

The most plausible explanation for the T2 signal-intensity hyperintensity along the hemispheric white matter in or around the corticospinal tract is the presence of mild brain edema, which is further supported from the results of a recent study, which, by using a coregistered MR imaging technique, demonstrated an increase in ventricular volume following medical treatment of HE. ${ }^{98}$

The T2 signal-intensity changes observed in some patients with cirrhosis are quite similar to those observed in amyotrophic lateral sclerosis, in which the pathologic bases are axonal loss, demyelination, or wallerian degeneration. ${ }^{99}$ However, none of these pathologic features have been described in association with $\mathrm{HE}$. Moreover, the ${ }^{1} \mathrm{H}-\mathrm{MR}$ spectroscopic findings of normal $\mathrm{N}$-acetylaspartate indices (a neuronal marker) and low concentrations of choline-containing compounds indicate preservation of axonal attenuation and lack of demyelinating processes (Fig 1). ${ }^{57}$ The progressive normalization of 

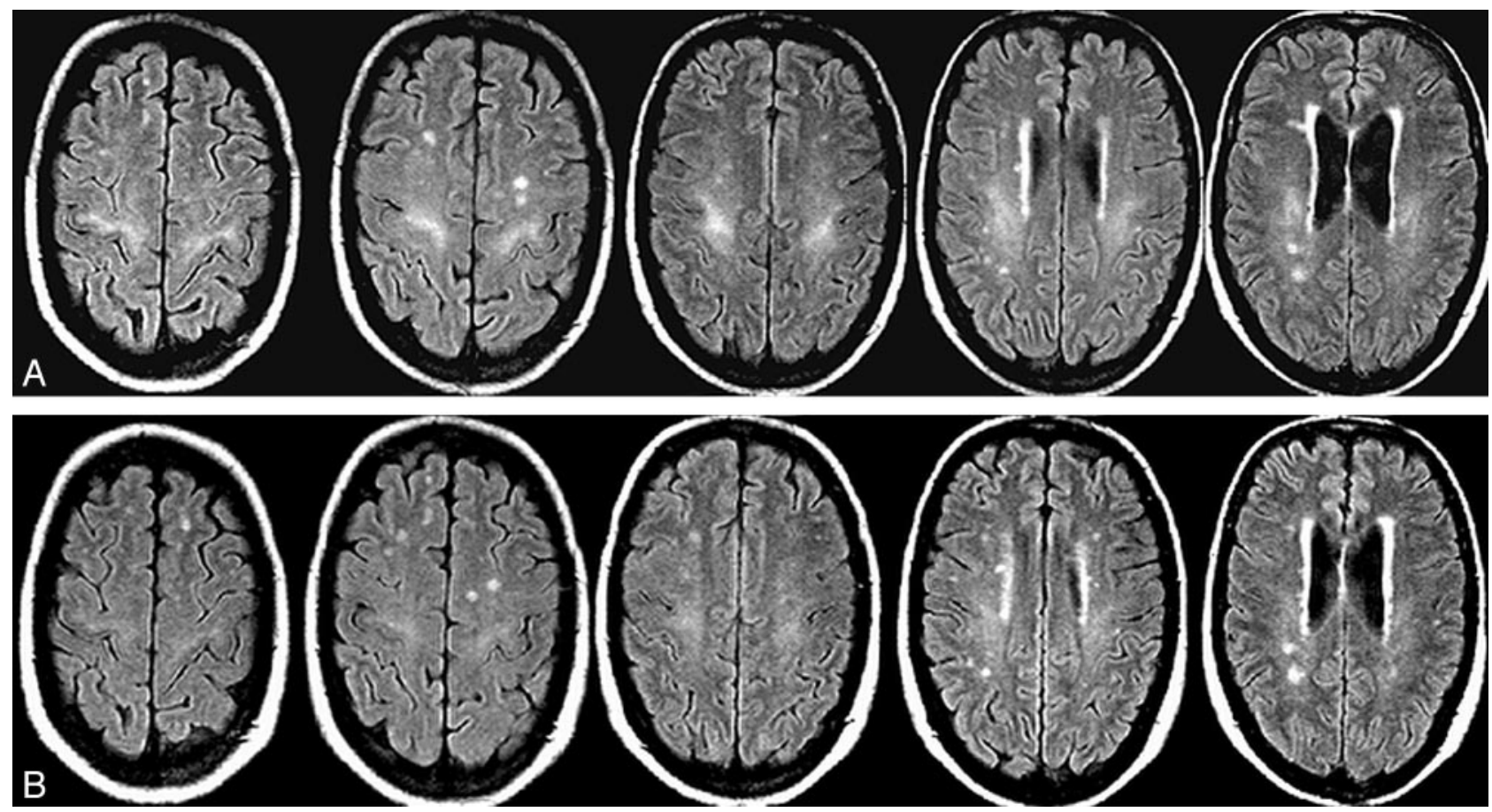

Fig 3. A, Transverse T2-weighted fast FLAIR images obtained in a patient with liver cirrhosis during an episode of hepatic encephalopathy. Observe the symmetric areas of increased signal intensity along the corticospinal tract in both cerebral hemispheres. $B$, This signal-intensity abnormality almost completely reverses on a follow-up study obtained few months later, when the patient showed no signs of overt hepatic encephalopathy.

the high-signal-intensity abnormalities in patients with cirrhosis after successful liver transplantation (Fig 2) ${ }^{84}$ further supports the hypothesis that edema is the main cause because resolution of demyelination and axonal loss would not be expected after restoration of liver function.

The selective involvement of the white matter within or close to the corticospinal tract observed in patients with cirrhosis may be simply due to a low threshold for visual detection of a widespread white matter alteration because fast FLAIR sequences are able to trace this tract as a faint symmetric signal-intensity increase in approximately half of healthy adults. ${ }^{96}$ Alternatively, this selective involvement may reflect a higher vulnerability of this white matter for the development of edema secondary to liver failure. In fact, pyramidal signs are frequently observed in $\mathrm{HE}^{7}$; thus, selective involvement of the corticospinal tract in a preclinical state of hepatic encephalopathy could be expected. The reasons for this greater vulnerability of the corticospinal tract are unknown, but they may include higher energy demands and higher susceptibility for excitotoxicity. ${ }^{100-102}$

Involvement of the corticospinal tract on fast FLAIR imaging correlates with abnormalities of transcranial magnetic stimulation (TMS), a noninvasive neurophysiologic method that assesses central motor pathway function. ${ }^{103}$ In patients with cirrhosis without overt HE-significant TMS shows increases in central motor conduction time and motor cortical threshold and decreases in motor-evoked potential amplitude. ${ }^{76}$ These TMS abnormalities reverse in parallel with the signal intensity of the corticospinal tract on fast FLAIR images after liver transplantation, indicating that this signal-intensity abnormality in patients with chronic liver disease is associated with subclinical functional abnormalities of the corticospinal tract.
White matter focal T2-weighted lesions (WMLs) may be also present in patients with liver cirrhosis with or without overt HE. These lesions resemble those commonly seen in patients with different types of cerebrovascular small-vessel disease (arteriolosclerosis, cerebral amyloid angiopathy, or cerebral autosomal dominant arteriopathy with subcortical infarcts and leukoencephalopathy) and in the healthy elderly population (Fig 4). ${ }^{104}$ Due to their location and small size, WMLs in patients with cirrhosis can be easily ignored or interpreted as normal involutive or chronic ischemic changes. However in patients with cirrhosis, these lesions decreased their volume with the improvement of $\mathrm{HE}^{105}$ or after liver transplantation, ${ }^{106}$ a fact that is closely correlated with the improvement of neuropsychological function (Fig 4). The partial reversibility of these focal WMLs is on the opposite side of what occurs with focal WMLs attributable to cerebrovascular small-vessel disease. Particularly in patients with hypertension and diabetes, WMLs may increase with time, but never decrease ${ }^{107-109}$ and, therefore, are permanently visible on MR imaging, indicating that they represent irreversible tissue damage. The decrease in the volume of WMLs observed in patients with cirrhosis can be explained by changes in the amount of brain edema. It is plausible that liver failure is responsible for low-grade brain edema, which could be exacerbated in areas of small-vessel disease and reverse after liver transplantation.

\section{DWI}

MTR and fast FLAIR sequences are highly sensitive in detecting an increase in net water content in the brain tissue. However, they cannot distinguish whether this increase is intracellular or extracellular and, therefore, cannot fully support the theory that mild brain edema in chronic liver failure is second- 

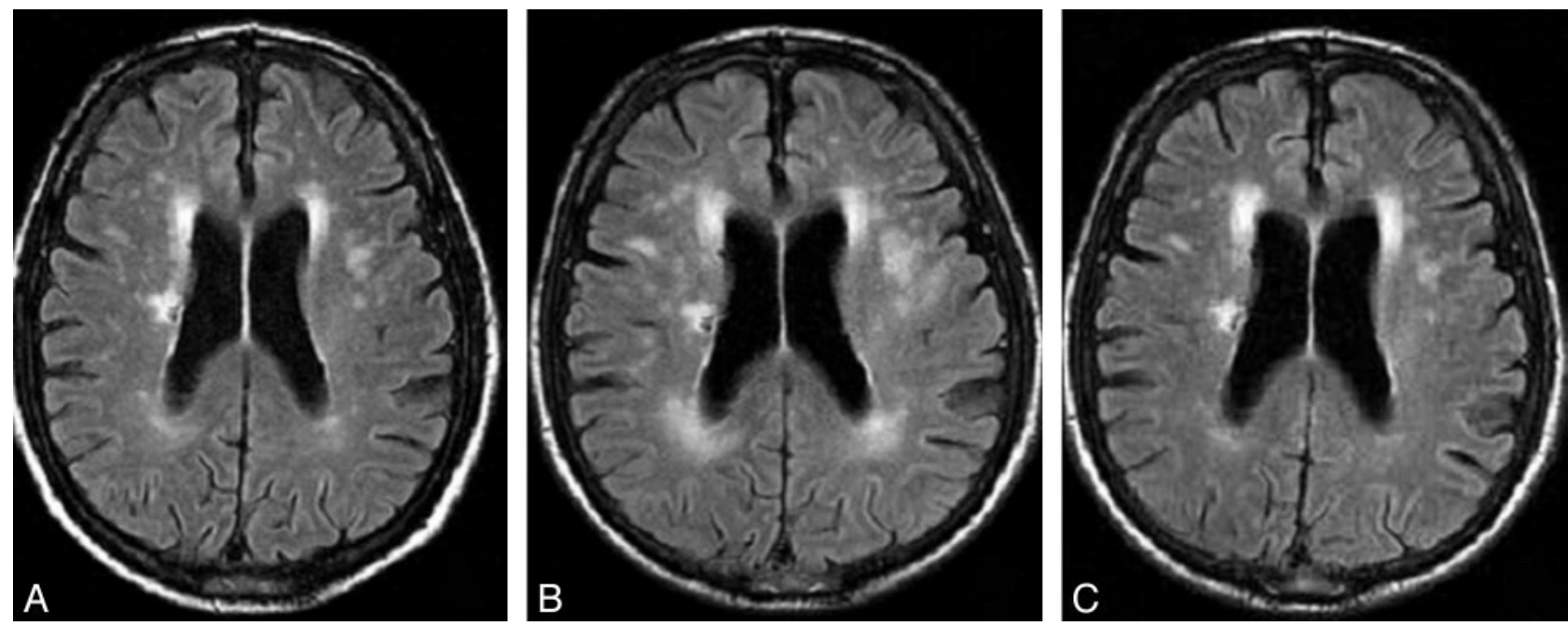

Fig 4. $A$, Baseline MR imaging study (transverse fast FLAIR T2-weighted image) of a 56-year-old patient with hepatitis $C$ cirrhosis without overt hepatic encephalopathy. Multiple focal WMLs in both cerebral hemispheres are attributed to small-vessel disease. B, A new scan obtained 2 years later during an episode of hepatic encephalopathy shows marked increase in the size of these focal WMLs. C, A new follow-up scan after complete resolution of neurologic symptoms shows a decrease in the size of the WMLs. This last scan was almost identical to the first study. A lacunar infarct is seen in the deep right frontal white matter.

\begin{tabular}{|c|c|c|c|c|c|}
\hline & T1WI Sequence & ${ }^{1} \mathrm{H}-\mathrm{MR}$ spectroscopy & MTR & T2/FLAIR Sequence & DWI \\
\hline $\begin{array}{l}\text { MR imaging } \\
\quad \text { abnormalities }\end{array}$ & $\begin{array}{l}\text { Bilateral, symmetric high } \\
\text { signal intensity of the } \\
\text { globus pallidus and } \\
\text { substantia nigra }\end{array}$ & $\begin{array}{l}\text { Increase in glutamine/ } \\
\text { glutamate signal; } \\
\text { depletion of myo- } \\
\text { inositol signal; } \\
\text { decrease in choline } \\
\text { signal; normal NAA } \\
\text { signal }\end{array}$ & $\begin{array}{l}\text { Mild (10\%) and diffuse } \\
\text { decrease in normal- } \\
\text { appearing white matter }\end{array}$ & $\begin{array}{l}\text { Diffuse white matter high } \\
\text { signal intensities } \\
\text { involving predominantly } \\
\text { the hemispheric } \\
\text { corticospinal tract; } \\
\text { focal high-signal T2 } \\
\text { lesions in subcortical } \\
\text { hemispheric white } \\
\text { matter }\end{array}$ & $\begin{array}{l}\text { Increase mean diffusivity } \\
\text { in hemispheric white } \\
\text { matter; normal } \\
\text { fractional anisotropy }\end{array}$ \\
\hline Pathogenesis & $\begin{array}{l}\text { Increased brain tissue } \\
\text { concentration of } \\
\text { manganese }\end{array}$ & $\begin{array}{l}\text { Osmolar adaptation of } \\
\text { intra-astrocytic } \\
\text { accumulation of } \\
\text { glutamine }\end{array}$ & $\begin{array}{l}\text { Mild and diffuse brain } \\
\text { edema }\end{array}$ & $\begin{array}{l}\text { Mild and diffuse brain } \\
\text { edema }\end{array}$ & Interstitial brain edema \\
\hline $\begin{array}{l}\text { Functional } \\
\text { consequences }\end{array}$ & $\begin{array}{l}\text { Parkinsonism } \\
\text { (particularly if } \\
\text { substantia nigra is } \\
\text { involved) }\end{array}$ & $\begin{array}{l}\text { Overt hepatic } \\
\text { encephalopathy } \\
\text { (particularly with } \\
\text { increase in } \\
\text { glutamine/glutamate) }\end{array}$ & $\begin{array}{l}\text { Functional abnormalities of } \\
\text { the corticospinal tract } \\
\text { on TMS }\end{array}$ & $\begin{array}{l}\text { Functional abnormalities } \\
\text { of the corticospinal } \\
\text { tract on TMS; } \\
\text { cognitive impairment }\end{array}$ & Cognitive impairment \\
\hline
\end{tabular}

Note:-T1WI Indicates T1-weighted imaging; NAA, N-acetylaspartate; TMS, transcranial magnetic stimulation; FLAIR, fluid-attenuated inversion recovery; DWI, diffusion-weighted imaging; MTR, magnetization transfer ratio.

ary to astrocyte swelling. This issue could be resolved by DWI, which could potentially locate the compartment where the water increase is more prominent.

Recent data on the use of mean diffusivity measurements within normal-appearing white matter of patients with cirrhosis have yielded unexpected results. Different studies have shown significant increase in brain water diffusivity, which was more pronounced with increasing grade of HE. ${ }^{85,86,110}$ These diffusivity values correlated with neuropsychological impairment and with serum venous ammonia. These findings, according to the basic understanding of diffusivity, ${ }^{111}$ probably reflect an accumulation of water in the extracellular compartment and, therefore, do not support the hypothesis of astrocytic swelling as the cause of diffuse brain edema in chronic liver failure.

The exact mechanism of this increase in extracellular fluid is not known. Plausible explanations would be the extracellu- lar migration of the macromolecules during the cellular osmoregulatory mechanism induced by the increase in astrocytic glutamate or an increased blood-brain barrier permeability. In fact, hyperammonemia may induce an increase in blood-brain barrier permeability, ${ }^{112}$ which will tend to favor cerebral capillary water influx to the brain. Moreover, Alzheimer type II astrocytes, a common abnormality in HE that was interpreted as a sign of astrocyte swelling, may correspond indeed to cellular damage and lose of cellular shape caused by oxidative stress, instead of intracellular edema. ${ }^{113}$ Another proposed explanation is that exposure of the brain to ammonia results in reduced expression of genes coding for key astrocytic proteins, such as the structural glial fibrillary acidic protein (GFAP), a cytoplasmatic filamentous protein that constitutes a major integral part of the cellular component in mature astrocytes. ${ }^{114,115}$ Reduced expression of GFAP induces morphologic changes in astrocytes, favoring diffusivity in the 
extracellular space. ${ }^{116}$ In acute liver failure, mean diffusivity values have been shown to be reduced ${ }^{117}$ therefore supporting an increased cell volume secondary to massive intra-astrocytic increase of glutamine as the mechanism of brain edema. Therefore, 2 different type of brain edema may exist in liver failure, intracellular in acute forms and probably interstitial in chronic forms.

\section{Conclusions}

Different MR imaging data obtained in patients with different types of liver failure have improved our understanding of the pathogenesis of HE, such as the involvement of manganese deposition in parkinsonism and the development of mild grade cerebral edema and osmotic abnormalities secondary to the increase in brain ammonia (Table 3). All these data support the use of MR imaging as a useful tool to study the pathogenesis of HE in humans, for the adequate interpretation of cognitive impairment in patients with cirrhosis, and for assessing the effects of therapeutic measures focused in correcting this disorder.

\section{Acknowledgment}

We thank Celine Cavallo for English language assistance.

\section{References}

1. Cordoba J, Blei AT. Hepatic encephalopathy. In: Shiff ER, Sorrell MF, Maddrey WC, eds. Shiff's Diseases of the Liver. Philadelphia: Lippincott Williams \& Wilkins; 2003:595-623

2. Ferenci P, Lockwood A, Mullen K, et al. Hepatic encephalopathy: definition, nomenclature, diagnosis, and quantification-final report of the working party at the 11th World Congresses of Gastroenterology, Vienna, 1998. Hepatology 2002;35:716-21

3. Weissenborn K. Diagnosis of encephalopathy. Digestion 1998;59(suppl 2):22-24

4. Cadranel JF, Lebiez E, Di Martino V, et al. Focal neurological signs in hepatic encephalopathy in cirrhotic patients: an underestimated entity? Am J Gastroenterol 2001;96:515-18

5. Joebges EM, Heidemann M, Schimke N, et al. Bradykinesia in minimal hepatic encephalopathy is due to disturbances in movement initiation. $J$ Hepatol 2003;38:273-80

6. Krieger S, Jauss $M$, Jansen $O$, et al. Neuropsychiatric profile and hyperintense globus pallidus on T1-weighted magnetic resonance images in liver cirrhosis. Gastroenterology 1996;111:147-55

7. Adams RD, Foley JM. The neurological disorder associated with liver disease. Res Publ Assoc Res Nerv Ment Dis 1953;32:198-237

8. Ortiz M, Jacas C, Cordoba J. Minimal hepatic encephalopathy: diagnosis, clinical significance and recommendations. J Hepatol 2005;42(suppl 1):S45-S53

9. Amodio P, Montagnese S, Gatta A, et al. Characteristics of minimal hepatic encephalopathy. Metab Brain Dis 2004;19:253-67

10. Weissenborn K, Ennen JC, Schomerus H, et al. Neuropsychological characterization of hepatic encephalopathy. J Hepatol 2001;34:768-73

11. Weissenborn $\mathrm{K}$, Bokemeyer M, Ahl B, et al. Functional imaging of the brain in patients with liver cirrhosis. Metab Brain Dis 2004;19:269-80

12. Albrecht J, Jones EA. Hepatic encephalopathy: molecular mechanisms underlying the clinical syndrome. J Neurol Sci 1999;170:138-46

13. Butterworth RF. The neurobiology of hepatic encephalopathy. Semin Liver Dis 1996;16:235-44

14. Hazell AS. Astrocytes and manganese neurotoxicity. Neurochem Int 2002;41:271-77

15. Normandin L, Hazell AS. Manganese neurotoxicity: an update of pathophysiologic mechanisms. Metab Brain Dis 2002;17:375-87

16. Butterworth RF. Pathophysiology of hepatic encephalopathy: a new look at ammonia. Metab Brain Dis 2002;17:221-27

17. Rao KV, Norenberg MD. Cerebral energy metabolism in hepatic encephalopathy and hyperammonemia. Metab Brain Dis 2001;16:67-78

18. Papavasiliou PS, Miller ST, Cotzias GC. Role of liver in regulating distribution and excretion of manganese. Am J Physiol 1966;211:211-16

19. Stallings WC, Metzger AL, Pattridge KA, et al. Structure-function relationships in iron and manganese superoxide dismutases. Free Radic Res Commun 1991;12-13(Pt 1):259-68
20. Wedler FC, Tom R. Interactions of Mn (II) with mammalian glutamine synthetase. In: Schramm VL, Wedler FC, eds. Manganese in Metabolism and Enzyme Function. New York: Academic Press; 1986:221-38

21. Bentle LA, Lardy HA. Interaction of anions and divalent metal ions with phosphoenolpyruvate carboxykinase. J Biol Chem 1976;251:2916-21

22. Couper J. On the effects of black oxide of manganese when inhaled into the lungs. Br Ann Med Pharmacol 1837;1:41-42

23. Mena I, Marin O, Fuenzalida S, et al. Chronic manganese poisoning: clinical picture and manganese turnover. Neurology 1967;17:128-36

24. Barbeau A. Manganese and extrapyramidal disorders (a critical review and tribute to Dr. George C. Cotzias). Neurotoxicology 1984;5:13-35

25. Emara AM, el-Ghawabi SH, Madkour OI, et al. Chronic manganese poisoning in the dry battery industry. Br J Ind Med 1971;28:78-82

26. Yamada M, Ohno S, Okayasu I, et al. Chronic manganese poisoning: a neuropathological study with determination of manganese distribution in the brain. Acta Neuropathol 1986;70:273-78

27. Olanow CW, Good PF, Shinotoh H, et al. Manganese intoxication in the rhesus monkey: a clinical, imaging, pathologic, and biochemical study. $\mathrm{Neu}$ rology 1996;46:492-98

28. Spadoni F, Stefani A, Morello M, et al. Selective vulnerability of pallidal neurons in the early phases of manganese intoxication. Exp Brain Res 2000; 135:544-51

29. Rose C, Butterworth RF, Zayed J, et al. Manganese deposition in basal ganglia structures results from both portal-systemic shunting and liver dysfunction. Gastroenterology 1999;117:640-44

30. Burkhard PR, Delavelle J, Pasquier RD, et al. Chronic parkinsonism associated with cirrhosis: a distinct subset of acquired hepatocerebral degeneration. Arch Neurol 2003;60:521-28

31. Olanow CW. Manganese-induced parkinsonism and Parkinson's disease. Ann N Y Acad Sci 2004;1012:209-23

32. Shulman LM, Minagar A, Weiner WJ. Reversal of parkinsonism following liver transplantation. Neurology 2003;60:519

33. Calne D, Chu N, Huang C, et al. Manganism and idiopathic parkinsonism: similarities and differences. Neurology 1994;44:1583-86

34. Klos KJ, Ahlskog JE, Josephs KA, et al. Neurologic spectrum of chronic liver failure and basal ganglia $\mathrm{T} 1$ hyperintensity on magnetic resonance imaging probable manganese neurotoxicity. Arch Neurol 2005;62:1385-90

35. Morgan MY. Noninvasive neuroinvestigation in liver disease. Semin Liver Dis 1996;16:293-314

36. Pujol A, Pujol J, Graus F, et al. Hyperintense globus pallidus on T1-weighted MRI in cirrhotic patients is associated with severity of liver failure. Neurology 1993;43:65-69

37. Krieger S, Jauss M, Jansen $\mathrm{O}$, et al. MRI findings in chronic hepatic encephalopathy depend on portosystemic shunt: results of a controlled prospective clinical investigation. $J$ Hepatol 1997;27:121-26

38. Matsumoto S, Mori H, Yoshioka K, et al. Effects of portal-systemic shun embolization on the basal ganglia: MRI. Neuroradiology 1997;39:326-28

39. Butterworth RF, Spahr L, Fontaine S, et al. Manganese toxicity, dopaminergic dysfunction and hepatic encephalopathy. Metab Brain Dis 1995;10:259-67

40. Spahr L, Butterworth RF, Fontaine S, et al. Increased blood manganese in cirrhotic patients: relationship to pallidal magnetic resonance signal hyperintensity and neurological symptoms. Hepatology 1996;24:1116-20

41. Hauser RA, Zesiewicz TA, Rosemurgy AS, et al. Manganese intoxication and chronic liver failure. Ann Neurol 1994;36:871-75

42. Katsuragi T, Iseki E, Kosaka K, et al. Cerebrospinal fluid manganese concentrations in patients with symmetric pallidal hyperintensities on $\mathrm{T} 1$ weighted MRI. J Neurol Neurosurg Psychiatry 1999;66:551-52

43. Pomier-Layrargues G, Spahr L, Butterworth RF. Increased manganese concentrations in pallidum of cirrhotic patients. Lancet 1995;345:735

44. Krieger D, Krieger S, Jansen O, et al. Manganese and chronic hepatic encephalopathy. Lancet 1995;346:270-74

45. Mirowitz SA, Westrich TJ, Hirsch JD. Hyperintense basal ganglia on T1weighted MR images in patients receiving parenteral nutrition. Radiology 1991;181:117-20

46. Nagatomo S, Umehara F, Hanada K, et al. Manganese intoxication during total parenteral nutrition: report of two cases and review of the literature. J Neurol Sci 1999;162:102-05

47. Mirowitz SA, Westrich TG. Basal ganglia signal intensity alterations: reversal after discontinuation of parenteral manganese administration. Radiology 1992;185:535-36

48. Ejima A, Imamura T, Nakamura S, et al. Manganese intoxication during total parenteral nutrition. Lancet 1992;339:426

49. Josephs KA, Ahlskog JE, Klos KJ, et al. Neurologic manifestations in welders with pallidal MRI T1 hyperintensity. Neurology 2005;64:2033-39

50. Nolte W, Wiltfang J, Schindler CG, et al. Bright basal ganglia in T1-weighted magnetic resonance images are frequent in patients with portal vein thrombosis without liver cirrhosis and not suggestive of hepatic encephalopathy. J Hepatol 1998;29:443-49

51. Mínguez B, García-Pagán JC, Bosch J, et al. Noncirrhotic portal vein thrombosis exhibits neuropsychological and MR changes consistent with minimal hepatic encephalopathy. Hepatology 2006;43:707-14 
52. Ortiz M, Córdoba J, Alonso J, et al. Oral glutamine challenge and magnetic resonance spectroscopy in three patients with congenital portosystemic shunts. J Hepatol 2004;40:552-57

53. Devenyi AG, Barron TF, Mamourian AC. Dystonia, hyperintense basal ganglia, and high whole blood manganese levels in Alagille's syndrome. Gastroenterology 1994;106:1068-71

54. Lai PH, Chen C, Liang HL, et al. Hyperintense basal ganglia on T1-weighted MR imaging. AJR Am J Roentgenol 1999;172:1109-15

55. Lockwood AH, Weissenborn K, Butterworth RF. An image of the brain in patients with liver disease. Curr Opin Neurol 1997;10:525-33

56. Weissenborn K, Ehrenheim C, Hori A, et al. Pallidal lesions in patients with liver cirrhosis: clinical and MRI evaluation. Metab Brain Dis 1995;10:219-31

57. Córdoba J, Alonso J, Rovira A, et al. The development of low-grade cerebral edema in cirrhosis is supported by the evolution of $(1) \mathrm{H}$-magnetic resonance abnormalities after liver transplantation. J Hepatol 2001;35:598-604

58. Cordoba J, Olive G, Alonso J, et al. Improvement of magnetic resonance spectroscopic abnormalities but not pallidal hyperintensity followed amelioration of hepatic encephalopathy after occlusion of a large spleno-renal shunt. J Hepatol 2001;34:176-78

59. Naegele T, Grodd W, Viebahn R, et al. MR imaging and $1 \mathrm{H}$ spectroscopy of brain metabolites in hepatic encephalopathy: time-course of renormalization after liver transplantation. Radiology 2000;216:683-91

60. Cooper JL, Plum F. Biochemistry and physiology of brain ammonia. Physiol Rev 1987;67:440-519

61. Lockwood AH, Yap EW, Wong WH. Cerebral ammonia metabolism in patients with severe liver disease and minimal hepatic encephalopathy. J Cereb Blood Flow Metab 1991;11:337-41

62. Norenberg MD. Astroglial dysfunction in hepatic encephalopathy. Metab Brain Dis 1998;13:319-35

63. Martinez-Hernandez A, Bell KP, Norenberg MD. Glutamine synthetase: glial localization in brain. Science 1977;195:1356-85

64. Donovan JP, Shafer DF, Shaw BW Jr, et al. Cerebral oedema and increased intracranial pressure in chronic liver disease. Lancet 1998;351:719-21

65. McManus ML, Churchwell KB, Strange K. Regulation of cell volume in health and disease. $N$ Engl J Med 1995;333:1260-66

66. Butterworth RF, Giguere JF, Michaud J, et al. Ammonia: key factor in the pathogenesis of hepatic encephalopathy. Neurochem Pathol 1987;6:1-12

67. Haussinger D, Laubenberger J, Dahl S, et al. Proton magnetic resonance spectroscopy studies on human brain myoinositol in hypo-osmolarity and hepatic encephalopathy. Gastroenterology 1994;107:1475-80

68. Lee JH, Seo DW, Lee Y, et al. Proton magnetic resonance spectroscopy $(1 \mathrm{H}-$ MRS) findings for the brain in patients with liver cirrhosis reflect the hepatic functional reserve. Am J Gastroenterol 1999;94:2206-13

69. Laubenberger J, Häussinger D, Bayer S, et al. Proton magnetic resonance spectroscopy of the brain in symptomatic and asymptomatic patients with liver cirrhosis. Gastroenterology 1997;112:1610-16

70. Geissler A, Lock G, Fründ R, et al. Cerebral abnormalities in patients with cirrhosis detected by proton magnetic resonance spectroscopy and magnetic resonance imaging. Hepatology 1997;25:48-54

71. Ross BD, Jacobson S, Villamil F, et al. Subclinical hepatic encephalopathy: proton MR spectroscopic abnormalities. Radiology 1994;193:457-63

72. Kreis R, Ross BD, Farrow NA, et al. Metabolic disorders of the brain in chronic hepatic encephalopathy detected with H-1 MR spectroscopy. Radiology 1992;182:19-27

73. Köstler H. Proton magnetic resonance spectroscopy in portal-systemic encephalopathy. Metab Brain Dis 1998;13:291-301

74. Córdoba J, Gottstein J, Blei AT. Glutamine, myo-inositol, and organic brain osmolytes after portocaval anastomosis in the rat: implications for ammonia-induced brain edema. Hepatology 1996;24:919-23

75. Thomas MA, Huda A, Guze B, et al. Cerebral 1H MR spectroscopy and neurophsychologic status of patients with hepatic encephalopathy. AJR Am J Roentgenol 1998;171:1123-30

76. Cordoba J, Raguer N, Flavia M, et al. T2 hyperintensity along the corticospinal tract in cirrhosis relates to functional abnormalities. Hepatology 2003;38:1026-33

77. Córdoba J, Blei AT. Brain edema and hepatic encephalopathy. Semin Liver Dis 1996;16:271-80

78. Haussinge D, Kircheis G, Fischer R, et al. Hepatic encephalopathy in chronic liver disease: a clinical manifestation of astrocyte swelling and low-grade cerebral edema? J Hepatol 2000;32:1035-38

79. Jalan R, Dabos K, Redhead DN, et al. Elevation of intracranial pressure following transjugular intrahepatic portosystemic stent-shunt for variceal haemorrhage. J Hepatol 1997;27:928-33

80. Swain MS, Blei AT, Butterworth RF, et al. Intracellular $\mathrm{pH}$ rises in astrocytes swell after portocaval anastomosis in rats. Am J Physiol 1991;261:R1491-96

81. Norenberg MD. The astrocyte in liver disease. In: Fedoroff S, Hertz L, eds. Advances in Cellular Neurobiology. New York: Academic Press; 1981:303-52

82. Iwasa M, Kinosada Y, Nakatsuka A, et al. Magnetization transfer contrast of various regions of the brain in liver cirrhosis. AJNR Am J Neuroradiol 1999;20:652-54

83. Rovira A, Grivé E, Pedraza S, et al. Magnetization transfer ratio values and proton MR spectroscopy of normal-appearing cerebral white matter in patients with liver cirrhosis. AJNR Am J Neuroradiol 2001;22:1137-42

84. Rovira A, Cordoba J, Sanpedro F, et al. Normalization of T2 signal abnormalities in hemispheric white matter with liver transplant. Neurology 2002;9:335-41

85. Lodi R, Tonon C, Stracciari A, et al. Diffusion MRI shows increased water apparent diffusion coefficient in the brains of cirrhotics. Neurology 2004;62:762-66

86. Kale RA, Gupta RK, Saraswat VA, et al. Demonstration of interstitial cerebral edema with diffusion tensor MR imaging in type $\mathrm{C}$ hepatic encephalopathy. Hepatology 2006;43:698-706

87. Wolf SD, Balaban RS. Magnetization transfer imaging: practical aspects and clinical applications. Radiology 1994;192:593-99

88. Dousset V, Grossman RI, Ramer KN, et al. Experimental allergic encephalomyelitis and multiple sclerosis: lesion characterization with magnetization transfer imaging. Radiology 1992;182:483-91

89. Dousset V, Brochet B, Vital A, et al. Lysolecithin-induced demyelination in primates: preliminary in vivo study with $\mathrm{MR}$ and magnetization transfer. AJNR Am J Neuroradiol 1995;16:225-31

90. Dousset V, Armand JP, Lacoste D, et al. Magnetization transfer study of HIV encephalitis and progressive multifocal leukoencephalopathy. AJNR Am J Neuroradiol 1997;18:895-901

91. van Waesberghe JH, van Walderveen MA, Castelijns JA, et al. Patterns of lesion development in multiple sclerosis: longitudinal observations with T1weighted spin-echo and magnetization transfer MR. AJNR Am J Neuroradio 1998;19:675-83

92. Rovira A, Alonso J, Cucurella G, et al. Evolution of multiple sclerosis lesion on serial contrast-enhanced T1-weighted and magnetization-transfer MR images. AJNR Am J Neuroradiol 1999;20:1939-45

93. Iwasa M, Kinosada Y, Watanabe S, et al. Hepatic cirrhosis: magnetization transfer contrast in globus pallidus. Neuroradiology 1998;40:145-49

94. Lee YC, Markus R, Hughes A. MRI in ALS: corticospinal tract hyperintensity. Neurology 2003;61:1600

95. Rydberg JN, Hammond CA, Grimm RC, et al. Initial experience in MR imaging of the brain with a fast fluid-attenuated inversion-recovery pulse sequence. Radiology 1994;193:173-80

96. Mirowitz S, Sartor K, Gado M, et al. Focal signal-intensity variations in the posterior internal capsule: normal MR findings and distinction from pathological findings. Radiology 1989;172:535-39

97. Gawne-Cain ML, Silver NC, Moseley IF, et al. Fast FLAIR of the brain: the range of appearances in normal subjects and its application to quantification of white-matter disease. Neuroradiology 1997;39:243-49

98. Patel N, White S, Dhanjal NS, et al. Changes in brain size in hepatic encephalopathy: a coregistered MRI study. Metab Brain Dis 2004;19:431-45

99. Sarchielli P, Pelliccioli GP, Tarducci R, et al. Magnetic resonance imaging and 1H-magnetic resonance spectroscopy in amyotrophic lateral sclerosis. $\mathrm{Neu}$ roradiology 2001;43:189-97

100. Shaw PJ, Eggett CJ. Molecular factors underlying selective vulnerability of motor neurons to neurodegeneration in amyotrophic lateral sclerosis. I Neurol 2000;247:17-27

101. Vogels BA, Maas MA, Daalhuisen J, et al. Memantine, an non-competitive NMDA-receptor antagonist improves hyperammonemia-induced encephalopathy and acute hepatic encephalopathy in rats. Hepatology 1997;25:820-27

102. Knecht K, Michalak A, Rose C, et al. Decreased glutamate transporter (GLT-1) expression in frontal cortex of rats with acute liver failure. Neurosc Lett 1997;229:201-03

103. Weber M, Eisen AA. Magnetic stimulation of the central and peripheral nervous systems. Muscle Nerve 2002;25:160-75

104. de Leeuw FE, de Groot JC, Achten E, et al. Prevalence of cerebral white matter lesions in elderly people: a population based magnetic resonance imaging study-The Rotterdam Scan Study. J Neurol Neurosurg Psychiatry 2001;70:9-14

105. Mínguez B, Rovira A, Alonso J, et al. Decrease in the volume of white matter lesions with improvement of hepatic encephalopathy. AJNR Am J Neuroradiol 2007;28:1499-500

106. Rovira A, Mínguez B, Córdoba J, et al. Decreased white matter lesion volume and improved cognitive function following liver transplantation. Hepatology 2007;46:1485-90

107. Schmidt R, Enzinger C, Ropele S, et al, for the Austrian Stroke Prevention Study. Progression of cerebral white matter lesions: 6-year results of the Austrian Stroke Prevention Study. Lancet 2003;361:2046-48

108. Taylor WD, MacFall JR, Provenzale JM, et al. Serial MR imaging of volumes of hyperintense white matter lesions in elderly patients: correlation with vascular risk factors. AJR Am J Roentgenol 2003;181:571-76

109. Dufouil C, Chalmers J, Coskun O, et al. Effects of blood pressure lowering on cerebral white matter hyperintensities in patients with stroke: the PROGRESS (Perindopril Protection Against Recurrent Stroke Study) Magnetic Resonance Imaging Substudy. Circulation 2005;112:1644-50. Epub 2005 Sep 6

110. Miese F, Kircheis G, Wittsack HJ, et al. 1H-MR spectroscopy, magnetization 
transfer, and diffusion-weighted imaging in alcoholic and nonalcoholic patients with cirrhosis with hepatic encephalopathy. AJNR Am J Neuroradiol 2006;27:1019-26

111. Schaefer PW, Grant PE, Gonzalez RG. Diffusion-weighted MR imaging of the brain. Radiology 2000;217:331-45

112. Ziylan YZ, Uzum G, Bernard G, et al. Changes in the permeability of the blood-brain barrier in acute hyperammonemia: effect of dexamethasone. Mol Chem Neuropathol 1993;20:203-18

113. Hazell AS, Normandin L, Norenberg MD, et al. Alzheimer type II astrocytic changes following sub-acute exposure to manganese and its prevention by antioxidant treatment. Neurosci Lett 2006;396:167-71
114. Sobel RA, DeArmond SJ, Forno LS, et al. Glial fibrillary acidic protein in hepatic encephalopathy: an immunohistochemical study. J Neuropathol Exp Neurol 1981;40:625-32

115. Eng LF, Ghirnikar RS, Lee YL. Glial fibrillary acidic protein: GFAP-thirty-one years (1969-2000). Neurochem Res 2000;25:1439-51

116. Chen KC, Nicholson C. Changes in brain cell shape create residual extracellular space volume and explain tortuosity behavior during osmotic challenge. Proc Natl Acad Sci U S A 2000;97:8306-11

117. Ranjan P, Mishra AM, Kale R, et al. Cytotoxic edema is responsible for raised intracranial pressure in fulminant hepatic failure: in vivo demonstration using diffusion-weighted MRI in human subjects. Metab Brain Dis 2005;20:181-92 